\title{
A CORRESPONDÊNCIA DE CHARLES BAUDELAIRE: PISTAS PARA SUA POÉTICA DO TRADUZIR
}

\author{
Álvaro Faleiros
}

\section{Introdução}

O poeta francês Charles Baudelaire (1821-1867) é também conhecido por suas traduções de Edgar Allan Poe, de quem traduziu, além do poema "O Corvo", em torno de cinquenta contos, reunidos em três volumes: Histoires extraordinaires (1856), Nouvelles Histoires Extraordinaires (1857) e Histoires Grotesques et sérieuses (1865). Baudelaire publicou eventualmente outras traduções, dentre as quais merecem destaque as traduções dos textos Confessions of an English Opium-eater e de Suspiria de Profundis do poeta romântico De Quincey, inseridas em seu livro Les Paradis artificiels (1860).

Em cada uma de suas traduções, Baudelaire adota posturas tradutórias aparentemente distintas. Na primeira, por afinidade e por admiração em relação à obra de Poe, o poeta francês assume uma postura que tem, por um lado, a função de divulgar a obra de Poe e assinalar a afinidade entre os autores e, por outro, um interesse em trazer o autor de forma mais literal, sem contudo desconsiderar as especificidades da língua francesa. No segundo caso, Baudelaire adota uma atitude mais antropofágica, incorporando os textos de De Quincey a sua própria obra, às vezes parafraseando-o, às vezes citando-o literalmente, às vezes editando-o por meio de omissões.

Com efeito, Baudelaire deixou poucos os registros sobre seu trabalho de tradução, sendo a maioria passagens de cartas. O desafio é, por meio desses trechos de sua correspondência, deduzir seu projeto tradutório.

\section{Em torno de Edgard Allan Poe}

O trabalho de tradução de Baudelaire está, no caso de Poe, diretamente ligado à própria poética do autor. Tanto é que Baudelaire, à época, chegou a ser acusado de ser um imitador do escritor americano. Incomodado com tal afirmação, em Carta, de 20 de junho de 1864, a Théophile Thoré, Baudelaire (1973b: 386) inverte a questão: 
...on m'accuse, moi, d'imiter Edgar Poe! Savez-vous pourquoi j'ai si patiemment traduit Edgar Poe? Parce qu'il me ressemblait.

... acusam-me, a mim, de imitar Edgard Poe! O Senhor sabe por que traduzi tão pacientemente Edgard Poe? Porque ele se parecia comigo.

Mesmo publicamente, Baudelaire fez questão de assumir a mesma postura, tanto é que, em parte do prefácio às histórias extraordinárias, quando se dirige ao leitor francês, se pode ler (POE, 1951: 1063):

... je suis fier et heureux d'avoir introduit dans leur mémoire un genre de beauté nouveau; et aussi bien, pourquoi n'avouerai-je pas que ce qui a soutenu ma volonté, c'était le plaisir de leur présenter un homme qui me ressemblait un peu, par quelques points, c'est-à-dire une partie de moi-même?

... estou orgulhoso e feliz de ter introduzido em sua memória um tipo novo de beleza; e também, por que não confessar que minha vontade de fazê-lo deveu-se ao prazer de apresentar um homem que se parecia um pouco comigo, em alguns aspectos, ou seja, uma parte de mim mesmo?

O projeto de Baudelaire tem, assim, um duplo sentido: por um lado, trata-se de divulgar Poe e, por outro, de fazer com que a afinidade entre os autores lance luz sobre sua poética e sua singularidade como autor. Curioso é que Poe não era à época autor conhecido no mundo anglófono, o que não intimidou de forma alguma Baudelaire. Pelo contrário, Baudelaire chamou para si a responsabilidade de valorizar a obra de Edgard Alan Poe. É o que se verifica na carta de 19 de março de 1856, anterior à publicação de As Flores do mal, enviada a seu tio, Sainte-Beuve, o grande crítico literário francês, na qual Baudelaire declara (1973a: 343):

Voici, mon cher protecteur, un genre de littérature qui peut-être ne vous inspirera pas d'autant d'enthousiasme qu'à moi, mais qui vous intéressera, à coup sûr. Il faut, c'est-à-dire je désire, qu'Edgar Poe, qui n'est pas grand-chose en Amérique, devienne un grand homme pour la France.

Veja, meu caro protetor, um tipo de literatura que talvez não lhe provoque tanto entusiasmo como em mim, mas que certamente lhe interessará. É preciso, isto é, desejo que Edgard Poe, que não é grande coisa nos Estados Unidos, torne-se um grande homem para a França.

Baudelaire acaba também por se perguntar sobre o alcance de seu trabalho de divulgação da obra de Poe, pois, para o leitor francês, começa divulgando a prosa e, para justificar a não tradução dos poemas de Poe, adverte (POE, 1951:1063): 
il me resterait à montrer Edgar Poe poète et Edgar Poe critique littéraire. Tout vrai amateur de poésie reconnaîtra que le premier de ces devoirs est presque impossible à remplir $[\ldots]$

faltaria ainda mostrar Edgard Poe poeta e Edgard Poe crítico literário. Todo verdadeiro amante de poesia reconhecerá que o primeiro desses deveres é quase impossível de realizar...

Baudelaire, que mais tarde traduzirá "O Corvo", está ciente da dificuldade de se traduzir poesia; o que assinalará não apenas em relação às suas próprias traduções, mas também em relação ao trabalho de tradutores que o antecederam. A questão central parece ser em que medida a língua estrangeira, com sua sintaxe própria, deve ser sentida na língua de chegada. A opção do poeta francês parece afinar-se com a percepção de que o texto deve ser naturalizado; pelo menos é esta sua impressão ao comentar outras traduções, em carta a Michel Lévy, de 9 de março de 1865, na qual confessa Baudelaire (1973b: 471):

Je viens de relire la détestable traduction faite en 1820 [de Melmoth the Wanderer], et sous le texte français on devine partout la phrase anglaise.

Acabo de reler a detestável tradução feita em 1820 [de Melmoth the Wanderer] e, sob o texto francês, é possível adivinhar em toda parte a frase inglesa.

Essa posição está em tensão com as escolhas do próprio Baudelaire enquanto tradutor, uma vez que, ao descrever o seu trabalho tradutório, o que se nota é sobretudo uma vontade de aproximação em relação ao texto de Poe, optando por uma tradução mais semântica. Essa escolha é pensada, tanto é que declara em La liberté de pensée, em 15 de julho de 1848 (apud: LEMONNIER, 1928:183):

Il faut surtout s'attacher à suivre le texte littéral ; certaines choses seraient devenues bien autrement obscures si j'avais voulu paraphraser mon auteur au lieu de me tenir servilement attaché à la lettre.

É necessário sobretudo procurar seguir o texto literalmente; algumas passagens teriam se tornado bastante obscuras se eu tivesse optado por parafrasear meu autor ao invés de me ater servilmente à letra.

Essa sua posição é confirmada em carta enviada a Michel Lévy, datada 15 de fevereiro de 1865, na qual escreve Baudelaire (1973b: 461): 
Vous pourrez, dans vos nombreuses relations, trouver un littérateur instruit qui vous fera une bonne et littérale traduction...

O senhor pode, dentre suas inúmeras relações, encontrar [em mim] um literato instruído que fará uma tradução boa e literal...

Em relação a sua oscilação entre naturalização e literalidade, Hennequet (2010), tem razão quando observa que: “A literalidade da tradução de Baudelaire parece, pois, limitada, em certa medida, por seu desejo de respeitar a língua de chegada".

A fronteira linguística não impede, contudo, Baudelaire de traduzir Poe a partir de princípios formais bastante livres, tanto é que, em sua tradução de "O Corvo", opta por uma sintaxe mais colada ao texto de partida; o que sugere que, para Baudelaire, o lugar de cada palavra no verso tem uma razão de ser e que modificar essa relação seria, de algum modo, distanciar-se da lógica textual pretendida por Poe.

Entretanto, para Ivo Barroso, em seu estudo sobre "O Corvo e suas traduções", os efeitos de aliteração do texto em inglês, não transpostos para o francês, seriam responsáveis pelo "malogro de traduzi-lo em prosa, como o fizeram Baudelaire e Mallarmé” (POE, 1998: 12). Esse tipo de crítica não compreende a escolha de Baudelaire, que produz um texto prosaico, registro que habita sua própria poética. A escolha de Baudelaire provoca, com efeito, um estranhamento, tanto retóricoformalmente quanto sintaticamente. Interessante é que, quando se trata de De Quincey, o projeto tradutório de Baudelaire, como foi indicado acima, parece ser de outra natureza.

\section{Em torno de Thomas De Quincey}

Como assinala Hennequet (2010), em seu importante trabalho sobre "Baudelaire tradutor de Poe", a tradução de Confessions of an English Opium-eater e de Suspiria de Profundis, de De Quincey, proposta por Baudelaire, encontra-se inserida nos Paraísos Artificiais, obra do próprio autor francês. Hennequet prossegue sua análise e nota que se trata de uma adaptação do texto de Thomas De Quincey, na qual há uma mistura de elementos traduzidos literalmente, havendo também elementos parafraseados e uma série de omissões. Essas liberdades, segundo Hennequet, explicam-se, em parte, por necessidades editoriais de se reduzir o tamanho livro. 
A justificativa pública encontra-se no prefácio de Les Paradis artificiels, no qual anuncia Baudelaire (In: Euvres complètes: 259):

Tel est le sujet du merveilleux livre que je déroulerai comme une tapisserie fantastique sous les yeux du lecteur. J'abrégerai sans doute beaucoup : De Quincey est essentiellement digressif (...) l'espace dont je dispose étant restreint, je serai obligé, à mon grand regret, de supprimer bien des hors-d'œuvre très amusants, bien des dissertations exquises, qui n'ont pas directement trait à l'opium...

Este é o assunto do maravilhoso livro que desenrolarei diante do leitor como uma tapeçaria fantástica. Terei de abreviá-lo bastante: De Quincey é essencialmente digressivo (...) o espaço de que disponho é restrito, serei assim obrigado, não sem pena, a suprimir várias entradinhas divertidas, várias deliciosas dissertações, que não tratam diretamente do ópio...

A imagem que Baudelaire constrói de Thomas de Quincey é positiva, pois, segundo seu tradutor francês, ele é obrigado a fazer uma série de cortes por necessidade, o que realiza "não sem pena", dando a impressão de que a "tapeçaria fantástica" de De Quincey de fato o maravilhava. Ao comparar as declarações públicas de Baudelaire com suas missivas, a impressão que se tem é outra. Por exemplo, na correspondência com Auguste Poulet-Malassis, datada de 18 de fevereiro de 1860, Baudelaire (1973a: 669) confessa:

Entre parenthèses, je vous dirai qu'il m'eût été agréable que vous me disiez votre sentiment sur la physionomie générale du livre [Les paradis artificiels] et en particulier sur l'Opium. De Quincey est un auteur affreusement conversationniste et digressionniste, et ce n'était pas une petite affaire que de donner à ce résumé une forme dramatique et d'y introduire de l'ordre. De plus, il s'agissait de fondre mes sensations personnelles avec les opinions de l'auteur original et d'en faire un amalgame dont toutes les parties fussent indiscernables.

Entre parênteses, gostaria que o senhor me dissesse o que pensa da fisionomia geral do livro [Les paradis artificiels], sobretudo na parte sobre o ópio. De Quincey é um autor por demais conversador e cheio de digressões, e não foi tarefa fácil dar a meu resumo uma forma dramática e ordenada. Além disso, tratava-se de fundir minhas sensações pessoais com as opiniões do autor original e de produzir um amálgama cujas partes fossem indissociáveis.

A postura antropofágica adotada por Baudelaire leva-o concretamente a fazer uma tradução "seletiva". Esta pode ser interpretada como uma necessidade editorial, mas, com efeito, ela condiz com as exigências estéticas de Baudelaire, autor muito mais conciso e claro do que o romântico inglês. Parece plausível deduzir, juntamente como Hennequet (2010) que, Baudelaire "quis guardar de De Quincey apenas o que 
lhe pareceu importante".

Desse modo, a explicação pública dada no prefácio parece ser mais uma desculpa do que um real interesse pela "fantástica tapeçaria do poema inglês".

\section{Considerações finais}

A leitura das cartas e das traduções de Baudelaire leva a crer que o autortradutor não possuía, em princípio, uma única poética do traduzir. Poética literal e reverente em relação à poesia de Poe; poética antropofágica e irreverente quando se trata de De Quincey. Essas distinções podem dar a impressão de que as duas poéticas do traduzir acima descritas não convergem. É importante, contudo, lembrar que Baudelaire é, acima de tudo, poeta, e não dos menores. Seu trabalho de tradução situase, pois, dentro de seu projeto estético. Fiel a sua poesia, Baudelaire, ao reverenciar Poe, reverencia a si mesmo e, pode-se até pensar que sua tradução não rimada nem metrificada abre caminho para seus poemas em prosa.

No caso de De Quincey, o que interessa a Baudelaire, como se pode notar em sua correspondência, não é a poética do autor, mas o trabalho que efetua em torno do ópio, ou seja, suas reflexões em torno da evasão. Este tema é tão caro a Baudelaire que Sellier (1971) chega a chamar Baudelaire de "une Bible de l'évasion". Nesse sentido, Baudelaire inventa seu próprio De Quincey, mais conciso e claro, de acordo com a estética moderna que molda em sua obra.

Enfim, as cartas de Baudelaire são, nesse sentido, simbólicas de seu projeto tradutório; projeto este que exige sempre do leitor, quando se trata de Baudelaire, a capacidade de encontrar correspondências.

\section{Referências bibliográficas}

BAUDELAIRE, Charles. Correspondance I. Paris: Pléiade, 1973a.

. Correspondance II. Paris: Pléiade, 1973 b.

. Euvres complètes. Paris: Robert Laffont, 2001.

HENNEQUET, Claire. Baudelaire traducteur de Poe. http://baudelaire-traducteurde-poe.blogspot.com/ (Acessado em setembro, 2010).

LEMONNIER, Léon. Les Traducteurs d'Edgar Poe en France de 1845 à 1875. Paris: Presses universitaires de France, 1928. 
POE, Edgard Allan Poe. Guvres en prose. Trad. Charles Baudelaire. Paris: Pléiade, 1951.

. "O Corvo" e suas traduções. Org. Ivo Barroso. Rio de Janeiro: Lacerda, 1998.

SELLIER, Philippe. L'évasion. Paris: Bordas, 1971. 